\title{
NAÇÃO, NAÇÕES: OS MODERNISTAS E A GERAÇÃ̃ DE 30
}

Luís Bueno

Universidade Federal do Paraná

$\mathrm{P}$

ouco se tem falado do forte embate que houve entre a geração surgida na década de 30 e os modernistas, e a tendência dominante é ver o romance de 30 como um desdobramento do modernismo de 22, uma segunda fase da literatura surgida na Semana de Arte Moderna.

Mais do que a qualquer outro crítico, coube a João Luiz Lafetá estabelecer o modelo que vê o romance de 30 como parte integrante do movimento modernista. Ele conseguiu criar uma forma de pensar que, de certa forma, harmoniza as diferenças entre os dois momentos. Seu ponto de partida é o de que todo movimento estético tem um projeto estético e um projeto ideológico. No caso do modernismo brasileiro teria ocorrido uma ênfase maior no projeto estético durante a fase heróica e, nos anos 30, a ênfase estaria no projeto ideológico:

Entretanto, não podemos dizer que haja uma mudança radical no corpo de doutrinas do Modernismo (...). As duas fases não sofrem solução de continuidade; apenas, como dissemos atrás, se o projeto estético, a 'revolução na literatura', é a predominante da fase heróica, a 'literatura na revolução' (para utilizar o eficiente jogo de palavras de Cortázar), o projeto ideológico, é empurrado, por certas condições políticas especiais, para o primeiro plano nos anos 30. (LAFETÁ, 1974, p. 19)

Mas pode dar resultados tentar pensar numa outra direção. Se olharmos em bloco as manifestações sobre o modernismo levadas a público pelos intelectuais - romancistas, poetas, críticos - dos anos 30, veremos que a recusa domi- 
nava, e não nos conduziu somente a uma certa poesia falsamente profunda que Lafetá denuncia em seu livro. Levou-nos também ao melhor do romance de 30. A Graciliano Ramos, por exemplo, cujas manifestações contrárias ao movimento modernistas são conhecidas.

Um levantamento do que os autores surgidos depois da revolução de outubro disseram do modernismo conduzirá a uma idéia central, repetida até à náusea, de que o movimento tinha um caráter destruidor, revelando-se incapaz de construir o que quer que fosse. Os verdadeiros construtores da arte nova, capazes de afrontar os preceitos da "nobre arte da escrita" ou ainda aqueles que fugiram das convenções lingüísticas redutoras não foram os participantes do movimento modernista, mas sim eles próprios: os autores do romance de $30 .{ }^{1}$

A formulação geral naquele momento é a de que a geração de 22 destruiu o academicismo e, com isso, executou tarefa importante mas não suficiente, já que ficou faltando a criação de uma nova arte brasileira. Em duas palavras, pode-se dizer que a literatura de 30 era vista como um alargamento do espírito de 22 , e a nova geração não se via, de maneira nenhuma, como integrante do movimento modernista: preferia ver-se como "pósmodernista”.

É bem nesse sentido, olhando para o modernismo a partir da década de 30, que talvez se possa acrescentar uma outra dimensão à proposição de João Luiz Lafetá. Como já se viu, ele parte do princípio da continuidade: para ele não há modernistas e pós-modernistas, como havia para os novos intelectuais dos anos 30, há apenas modernistas de duas fases. Para pensar as diferenças dentro desse movimento único, ele elabora a proposição de que num primeiro momento o que estava em foco era a renovação estética. Rompidas as resistências contra os novos procedimentos, que findaram por rotinizarse, a geração dos anos 30 priorizou o debate ideológico.

Para quem põe seu ponto de referência nos anos 30, não há como fugir da formulação de que temos dois momentos literários distintos. Isso pode

\footnotetext{
Apenas para deixar indicadas algumas manifestações coletivas desse ponto de vista: ver o número 4 da revista Lanterna Verde, de 1936, e o inquérito publicado nos números 21, 22 e 23 da Revista do Brasil, já em 1940. No início de "Literatura e subdesenvolvimento" Antonio Candido faz uma observação sobre as formas de ver o Brasil antes e depois da Revolução de 30:
} 
levar à consideração de que, para funcionar enquanto uma visão de continuidade, a proposta de Lafetá toma em sentido bastante amplo os conceitos de projeto ideológico e de projeto estético.

Pensando de forma rigorosa, a sustentação da proposição segundo a qual as transformações sofridas pela forma de fazer literatura no Brasil entre os decênios de 20 e de 30 não constituem dois momentos diferentes, mas duas fases de um só momento a se diferenciarem por uma ênfase maior no projeto estético ou no ideológico, depende de se entender que existe um mesmo projeto estético e um mesmo projeto ideológico. Se os projetos forem outros, não faz sentido pensar em mera diferença de ênfase. Quando um momento enfatiza um determinado projeto ideológico (ou estético), ele só pode ser continuidade de um momento anterior se nesse primeiro instante for possível localizar um mesmo projeto ideológico (ou estético), ainda que posto à sombra de um projeto estético (ou ideológico). No caso do modernismo, é inegável que a geração dos autores que participaram da Semana de Arte Moderna se preocupava sobretudo com uma revolução estética, enquanto os que estrearam nos anos 30 centravam sua atenção nas questões ideológicas. Não é muito fácil, no entanto, admitir uma continuidade dos projetos estético e ideológico de uma geração para outra de forma a que a ênfase num ou noutro desse conta dos desacordos que separam essas duas gerações. Seria preciso saltar as enormes diferenças que há entre os intelectuais formados antes da Primeira Guerra e os formados depois dela.

Mário Vieira de Mello, um dos poucos que abordaram o problema das relações entre subdesenvolvimento e cultura, estabelece para o caso brasileiro uma distinção que também é válida para toda a América Latina. Diz ele que houve alteração marcada de perspectivas, pois até mais ou menos o decênio de 1930 predominava entre nós a noção de país "novo", que ainda não pudera realizar-se, mas que atribuía a si mesmo grandes possibilidades de progresso futuro. Sem ter havido modificação essencial na distância que nos separa dos países ricos, o que predomina agora é a noção de "país subdesenvolvido". Conforme a primeira perspectiva, salientava-se a pujança virtual e, portanto, a grandeza ainda não realizada. Conforme a segunda, destaca-se a pobreza atual, a atrofia; o que falta, não o que sobra. (CANDIDO, 1987, p. 140) 
Se a distância que nos separa dos países ricos não se modificou, a mudança de perspectiva sobre o país corresponde a um deslocamento no plano ideológico: mudou a visão de Brasil. Mesmo com a ressalva de Antonio Candido de que, nos anos 30, ainda não havia exatamente uma consciência do subdesenvolvimento, apenas uma "pré-consciência", temos um afastamento ideológico considerável entre a geração que fez a Semana de Arte Moderna e a que escreveu o romance de 30. Essa diferença de visão dominante do país é elemento central nas diferentes formas de ação privilegiadas pelos modernistas e pelos romancistas de 30. Ora, a idéia de país novo, a ser construído, é plenamente compatível com o tipo de utopia que um projeto de vanguarda artística sempre pressupõe: ambos pensam o presente como ponto de onde se projeta o futuro. Uma consciência nascente de subdesenvolvimento, por sua vez, adia a utopia e mergulha na incompletude do presente, esquadrinhandoo, o que é compatível com o espírito que orientou os romancistas de 30 . Tais diferenças ficaram claras muitas vezes nas relações entre os intelectuais aparecidos nos anos 20 e os dos anos 30, e são testemunha disso a correspondência de Mário de Andrade com Murilo Miranda, um dos rapazes da Revista Acadêmica (ANDRADE, 1981), ou a avaliação repetida muitas vezes de que um livro como Macunaíma era um verdadeiro monstrengo estético. ${ }^{2}$

Sem discordar da formulação de que o romance de 30 é o momento da "literatura na revolução" e que o modernismo de 22 é o da a "revolução na literatura”, como propõe João Luiz Lafetá, o que se quer mostrar aqui é que esse aparentemente pequeno deslocamento de sentido pode ser entendido de outra forma: como demonstração de um afastamento dos projetos de cada geração e não de sua aproximação. Pensar que o modernismo é uma arte utópica e o romance de 30 é uma arte pós-utópica pode ajudar a esclarecer como isso se dá.

As tensões, as recusas forçadas, a aceitação mais ou menos disfarçada do movimento modernista foram elementos constituintes de uma dinâmica que pôde dar origem ao romance de 30, em toda sua diversidade. Se o desejo de fazer uma arte brasileira, incluindo o uso de uma linguagem mais 
coloquial e uma aproximação da realidade do país, é um dado de permanência do espírito de 22 durante a década de 30 , a realização estética em si mesma é muito diferente - e o predomínio do romance ao invés da poesia já é evidência suficiente desse fato. A forma de atuação é também outra. Os modernistas produziram manifestos e profissões de fé, fundaram revistas e formaram grupos, mesmo depois de terem sido percebidas as diferenças dentro do grande grupo inicial. Os escritores de 30 não produziram um único manifesto estético. A principal revista do período, o Boletim de Ariel, não era o espaço de manifestação de um grupo ou de um movimento: era, na verdade, um empreendimento comercial da Ariel Editora

Para entender essas diferenças pode ser útil voltar um pouco a algo apenas mencionado acima: aquela diferença entre as gerações formadas antes e depois da Primeira Guerra, articulada à dinâmica do funcionamento dos projetos de vanguarda. Em 1984, ao discutir o percurso do movimento concreto, de que foi um dos líderes, Haroldo de Campos vai aplicar ao caso brasileiro uma idéia segundo a qual todo movimento de vanguarda só pode existir afinado com algum tipo de utopia. Ele se vale mesmo de uma expressão de Ernst Bloch atribuída ao espírito de vanguarda, "princípio-esperança”, e o liga a um momento histórico de perspectiva de desenvolvimento - o Brasil dos anos 50 - para traçar seu raciocínio:

Sem esse princípio-esperança, não como vaga abstração, mas como perspectiva efetivamente alimentada por uma prática prospectiva, não pode haver vanguarda entendida como movimento. $\mathrm{O}$ trabalho em equipe, a renúncia às particularidades em prol do esfor $\div$ o coletivo e do resultado anônimo é algo que só pode ser movido por esse motor elpídico (do grego 'elpis', expectativa, esperança) (CAMPOS, 1984, p. 4).

A esse momento sucederia um outro, de fechamento político, que tende a diluir as esperanças:

Sem perspectiva utópica, o movimento de vanguarda perde o seu sentido. Nessa acepção, a poesia viável do presente é uma poesia de pós-vanguarda, não porque seja pós-moderna ou anti-moderna, mas porque é pósutópica. Ao projeto totalizador de vanguarda, que, no limite, só a utopia 
redentora pode sustentar, sucede a pluralização das poéticas possíveis. Ao princípio-esperança, voltado para o futuro, sucede o princípio-realidade, fundamente ancorado no presente. (CAMPOS, 1984, p. 5)

Como se vê, Haroldo de Campos lança mão de um jogo de conceitos muito novo àquela altura - o de “pós utópico", relacionado à derrocada dos regimes de esquerda no Leste Europeu redimensionando o sentido de "utópico" - e o define como um conceito de história literária aplicável aos movimentos de vanguarda em geral. Tomada em linhas gerais, essa idéia pode explicar muito do que aconteceu na transição dos anos 20 para os anos 30 . O projeto modernista nasceu em São Paulo e não há quem deixe de apontar o quanto do desenvolvimento industrial da cidade alimentou a esperança de que a modernização do país, quando generalizada, poderia até mesmo tirar da marginalidade as massas miseráveis. Em Macunaíma mesmo, o palco onde se dá o encontro prospectivo entre o início do desenvolvimento e o resgate da tradição ancestral é a cidade de São Paulo, lugar-símbolo dessa utopia modernista que deseja amalgamar numa feição presente de identidade nacional o passado que vale e o futuro que vai valer. Se olhamos para um autor como Plínio Salgado, em seu $O$ estrangeiro, veremos que em sentido diferente - e perigosamente diferente mais adiante - a utopia de fusão do primitivo com o moderno também está presente.

Esse tipo de utopia é possível numa mentalidade que percebe o Brasil ainda como país novo - para retomar os termos empregados por Antonio Candido em "Literatura e subdesenvolvimento". Em certo sentido, a mesma crença alimentou os movimentos sociais que desembocaram na revolução de 1930 . O resultado, no entanto, se revelou frustrante. Se é verdade que foram eliminados certos aspectos arcaicos da sociedade brasileira, também é verdade que foram apenas os que não podiam mais ser sustentados, e o regime de Vargas, resultado direto da revolução, não foi o vetor de qualquer transformação que pudesse confirmar as esperanças que a prepararam. Quando se associa essa frustração local à mentalidade anti-liberal que vai dominando a intelectualidade brasileira naquele momento, fica fácil perceber que a visão de país novo envelhece. Depois disso, olhar para o presente não é ver um cenário muito agradável - o que salta aos olhos é o atraso e a exclusão que a modernização já implementada não consegue cobrir. Daí certamente nasce aquela pré-consci- 
ência do subdesenvolvimento, ou seja, o início da percepção de que o presente não se modificará sem que algo se modifique na própria estrutura das relações sociais. A arte da década de 30 não poderá, portanto, abraçar qualquer projeto utópico e necessariamente se colocará como algo muito diverso do que os modernistas haviam levado a cabo. É nesse sentido que se pode dizer que o romance de 30 vai se constituir como uma arte pós-utópica.

Essa nova visada é localizável mesmo na obra dos escritores que participaram do movimento. Oswald muda bastante a direção de sua ficção com o projeto do Marco zero. Mário de Andrade planeja um livro, Café, que vai tomar como tema a decadência de uma família a partir de 1928, bem ao gosto do romance de 30. Para quem vê de hoje, não há como não lembrar do título do Cacau de Jorge Amado, sugerindo um romance que se articula com o andamento - ou não-andamento - da produção econômica relacionada ao principal produto agrícola da região que ambienta a história, o que até certo ponto se confirma na leitura do plano apresentado em carta a Moacyr Werneck de Castro em 1941. ${ }^{3}$

Do novo romance que surgiria na década de 30 está ausente qualquer crença na possibilidade de uma transformação positiva do país pela via da modernização. É em São Bernardo, de Graciliano Ramos, que se encontrará a expressão romanesca mais acabada dessa descrença na modernização, que vai junto com uma avaliação pouco otimista da revolução de 30 .

Paulo Honório acredita na modernização. Quando consegue se apossar de S. Bernardo, vai desenvolvê-lo com novas máquinas, novas técnicas de criação e plantio e mesmo com a introdução de novas culturas. É em pessoa o homem de negócios para quem nada serve só para ser bonito tudo, até as flores, visam ao lucro, e a certa altura ele se vangloria disso diante de d. Glória. Mas em nenhum ponto se encontrará maior desenvolvimento desse problema do que através de seu Ribeiro. O capítulo 7, que trata desse personagem, e já foi considerado uma excrescência no romance, na

Ver carta a Moacyr Werneck de Castro de 06/11/1941 (CASTRO, 1989, p. 183-185). Este é um projeto acidentado de Mário de Andrade. Nasceu como romance, em 1929, transformou-se em libreto de ópera a ser escrita por Francisco Mignone no início dos anos 30, voltou a ser romance em 1941 e terminou, em dezembro de 1942, tomando a forma de um poema dramático incluído nas Poesias Completas 
verdade oferece um contraponto ao caso do próprio Paulo Honório. Escrevendo num momento em que ele se vê atropelado pela marcha da história, é natural que o comova a história do velho manda-chuva de uma pequena povoação caído em desgraça. Para Paulo Honório, o infortúnio de seu Ribeiro foi não ter acompanhado a evolução inevitável da modernização. Depois de descrever a posição proeminente de seu Ribeiro diz:

Ora, essas coisas se passaram antigamente.

Mudou tudo. Gente nasceu, gente morreu, os afilhados do major cresceram e foram para o serviço militar, em estrada de ferro.

O povoado transformou-se em vila, a vila transformou-se em cidade, com chefe político, juiz de direito, promotor e delegado de polícia.

Trouxeram máquinas - e a bolandeira do major parou. (RAMOS, 1985, p. 37)

Não falta à caracterização feita por Paulo Honório a referência às máquinas - e em especial ao trem -, os grandes ícones da modernização. $\mathrm{O}$ engenho primitivo da bolandeira tinha que morrer diante do poder da automação. Por conseqüência, o poder do velho major teria que cair também. O que escapa a Paulo Honório - e mesmo alimenta a idéia de que, se ele quisesse, poderia se reerguer rapidamente - é que a sua própria ruína se deu apesar de ele ter acompanhado e até estado à frente de um processo de modernização da produção rural. O que o arruinou foi a falta de percepção de que de nada adiantam técnicas modernas diante de uma estrutura social que se mantém intocada - insensibilidade traduzida em sua absoluta incapacidade de compreender Madalena.

Nem mesmo para o mais otimista dos romancistas de 30 o tempo da utopia pode ser visível como fora para os modernistas, que o vislumbram a partir de um presente no qual conseguem identificar os prenúncios desse futuro ao mesmo tempo utópico e palpável. Com os pés fincados num presente que só faz poder prever o pior - inclusive a Guerra, da qual se falava desde a primeira metade da década - parece que até mesmo o militante tem que se conformar a adiar seu sonho para um futuro indeterminado.

Isso tudo pode ser mais bem percebido se projetado numa figura a que o romance de 30 dedicou toda sua energia de criação, o fracassado. Não é à toa que o primeiro a apontar a recorrência dessa figura, para reprová-la, 
seja um modernista, Mário de Andrade. Ele parece ter-se dado conta do problema em artigo escrito durante o período em que atuou como crítico no jornalismo carioca, mantendo a coluna "Vida Literária" no Diário de Notícias, quando tratava de um grupo de cinco novos romances. Depois de anotar o que lhe parecia digno de destacar em cada um dos cinco livros, propõe uma síntese que ultrapassa os lançamentos em questão, valendo como reflexão sobre toda a geração dos romancistas de $30:^{4}$

Mas vejo que acabei de empregar, pela segunda vez nesta crônica, a palavra "fracassado"...É estranho como está se fixando no romance nacional a figura do fracassado. Bem, entenda-se: pra que haja drama, pra que haja romance, há sempre que estudar qualquer fracasso, um amor, uma terra, uma luta social, um ser que faliu. Mas o que está se sistematizando, em nossa literatura, como talvez péssimo sintoma psicológico nacional, absolutamente não é isso. Um Dom Quixote fracassa, como fracassam Otelo e Mme. Bovary. Mas estes, e com eles quase todos os heróis do bom romance, são seres dotados de ideais, de grandes ambições, de forças morais, intelectuais ou físicas. São, enfim, seres capacitados para se impor, conquistar, vencer na vida, mas que diante de forças mais transcendentes, sociais ou psicológicas, se esfacelam, se morrem na luta. E não estará exatamente nisto, neste fracasso, na luta contra forças imponderáveis e fatais, o maior elemento dramático da novela? Mas em nossa novelística (e é possivel buscar bastante longe as raízes disto, num Dom Casmurro, por exemplo, ou sistematicamente num Lima Barreto) o que está se fixando, não é o fracasso proveniente de forças em luta, mas a descrição do ser incapacitado para viver, o indivíduo desfibrado, incompetente, que não opõe força pessoal nenhuma, nenhum elemento de caráter, contra as forças da vida, mas antes se entrega sem quê nem porquê à sua própria insolução. Será esta, por acaso, a profecia de uma nacionalidade desarmada para viver?... (ANDRADE, 1993, p. 181)

\footnotetext{
Lembrando que, desses cinco escritores analisados na crônica, pelo menos dois são autores de razoável sucesso nos anos 30. Fran Martins já publicara um livro de contos Manipueira, em 1933, e dois romances, Ponta de Rua (1936) e Poço dos Paus (1938). Cordeiro de Andrade, por sua vez, já publicara os romances Cassacos (1934) e Brejo (1936). Roberto Schwarz trata desta questão em Oswald de Andrade. Ver: SCHWARZ, 1987, p. 11-28.
} 
A importância dessa sua formulação ele logo percebeu. Tanto que, um ano depois, no primeiro número da revista Clima, dirigindo-se à intelectualidade que surgia nos anos 40, vai dar grande destaque a ela - e num texto que é um verdadeiro testamento para uma novíssima geração. Depois de reproduzir, numa versão revista, o parágrafo de seu artigo de 1940, citado acima, acrescenta: "Quando, ao denunciar este fenômeno, me servi quase destas mesmas palavras, julguei lhe descobrir algumas raízes tradicionais. Hoje estou convencido de que me enganei. O fenômeno não tem raízes que não sejam contemporâneas e não prolonga qualquer espécie de tradição” (ANDRADE, 1974, p. 190).

A hipótese de Mário de Andrade é a de que o fracasso domina o romance de 30 e define sua visão da nacionalidade. Contrapondo-a à sua própria visão de nacionalidade, é natural que vá considerá-la derrotista, vetor da desistência, "sintoma de que o homem brasileiro está às portas de desistir de si mesmo" (ANDRADE, 1974, p. 191), como dirá mais adiante. E ele acerta em cheio ao apontar o fracassado como a figura hegemônica no romance de 30. Mas há dois elementos importantes a serem discutidos a partir de sua formulação Andrade: a natureza do fracasso que domina o romance de 30 e sua articulação com uma idéia de identidade nacional.

Assim como não é adequado falar em otimismo ingênuo generalizado no romance de 30, não é muito apropriado identificar a exploração artística constante do fracasso à desistência. Trata-se antes de manifestação daquela avaliação negativa do presente, daquela impossibilidade de ver no presente um terreno onde fundar qualquer projeto que pudesse solucionar o que quer que seja enfim, é uma manifestação do que se está chamando aqui de espírito pós-utópico. A utopia está, então, adiada, mas não de todo afastada. Só será possível pensar qualquer utopia depois de mergulhar o mais profundamente possível nas misérias do presente. Esquadrinhar palmo a palmo as misérias do país: eis o que toma a peito fazer o romance de 30 . E isso não se coloca apenas no plano dos problemas sociais, onde se nota o fenômeno com mais clareza. Para quem, como Octávio de Faria, vê no presente o reino da miséria moral, há também uma recusa vigorosa da facilidade em se mudar esse presente. É sintomático que ele, no primeiro romance de um ciclo pensado para vários volumes - encerrou-se, em 1979, com o $13^{\circ}$ romance - mate atropelado o “anjo" Carlos Eduardo, o único dos adolescentes de Mundos Mortos que vence as tentações com facilidade - na verdade, seria até mais apropriado dizer que ele não vence essas 
tentações porque nem sequer as sente. E mais: ele morre exatamente no dia em que outros adolescentes resolveram armar uma verdadeira armadilha para sua santidade ao arrumar um encontro com uma bela prostituta para ver se ele seria capaz de resistir. Com a morte impedindo esse teste, o leitor não pode nem ter certeza se o anjo é mesmo um anjo, já que não passou por nenhuma provação maior. O que fica para o resto da Tragédia burguesa são os personagens vivendo no impasse, na dúvida, indo pendularmente do auto-controle à queda. É o caso de Ivo, o irmão de Carlos Eduardo, que protagoniza a cena de abertura de Mundos mortos em luta vã consigo mesmo para não cair na tentação de cometer o pecado de se masturbar.

Dessa preferência pelo impasse vem a particularidade do realismo praticado pelo romance de 30 em relação ao realismo do século XIX. É interessante pensar, por exemplo, num autor cultuadíssimo nos anos 30, Dostoiévski. Em Crime e castigo a ação positiva teorizada e praticada por Raskolnikoff redunda em fracasso. Mas o romance não acaba no conflito entre esse ser afirmativo que chega ao assassinato e as forças morais que o levam à confissão e à prisão. É preciso que ele, através do amor de Sônia, abrace a religião. E essa força positiva não fica guardada para um futuro remoto, mas já está em curso numa história palpável que poderia ser contada imediatamente. É com essa perspectiva, aliás, que o romance se fecha: "Mas aqui começa uma segunda história, da lenta transformação de um homem, da sua regeneração, da sua passagem gradual de um mundo para outro. Podia ser o motivo de uma nova narração. - A que quisemos oferecer ao leitor terminou aqui" (DOSTOIÉVSKI, 1941, p. 445).

Algo semelhante se passa nos romances do autor de língua portuguesa mais admirado entre nós naqueles anos, Eça de Queirós, para quem o debruçar sobre as desgraças do presente é uma forma de entreabrir as cortinas e vislumbrar o futuro. É exemplar, nesse sentido, o encerramento de $O$ crime do padre Amaro, em que o atraso português aparece contraposto ao avanço da França sacudida pela revolução de 1848 e ao Portugal das conquistas marítimas cantado por Camões:

- Vejam - ia dizendo o conde: - vejam toda esta paz, esta prosperidade, este contentamento... Meus senhores, não admira realmente que sejamos a inveja da Europa! 
E o homem de estado, os dois homens de religião, todos três em linha, junto às grades do monumento, gozavam de cabeça alta esta certeza gloriosa da grandeza do seu país, - ali ao pé daquele pedestal, sob o frio olhar de bronze do velho poeta, ereto e nobre, com os seus largos ombros de cavaleiro forte, a epopéia sobre o coração, a espada firme, cercado dos cronistas e dos poetas da antiga pátria - pátria para sempre passada, memória quase perdida! (QUEIRÓS, s.d., v.1, p. 345)

A solução é muito visível aqui: tomar o caminho do desenvolvimento das grandes nações européias, recuperar o espírito ativo de um Portugal que é “memória quase perdida”. Abraçar o futuro, lançar-se a ele lembrando-se do que fora capaz. Nos dois casos, há uma mudança possível e à vista. Mesmo em $O$ crime do padre Amaro, onde há a vitória clara do que há de pior em Portugal, oferece-se um caminho a trilhar capaz de reverter o fracasso da nação. Há um lugar, lá fora, em que se abdicou do "contentamento" para que se lançasse ao futuro e que pode servir de exemplo.

No caso do romance de 30, a formação da consciência de que o país é atrasado canalizou todas as forças. Produziram-se romances que se esgotavam ou na reprodução documental de um aspecto injusto da realidade brasileira ou no aprofundamento de uma mentalidade equivocada que contribuiria para a figuração desse atraso. O herói, ao invés de promover ações para transformar essa realidade negativa, servia para incorporar algum aspecto do atraso. Em $O$ Amanuense Belmiro ou em Angústia, é o intelectual que faz esse papel; em Os corumbas é o operário; em Vidas secas, o camponês; em Mundos mortos, a burguesia; em Mãos vazias ou em Amanhecer, a mulher. Ao contrário do realismo do século XIX, que havia estigmatizado a narrativa em primeira pessoa, muitas vezes o romance de 30 priorizou-a, com duplo efeito: primeiro, o de conferir veracidade maior ao documento, já que assim ele aparece construído como depoimento de quem viveu aquele fracasso; segundo, o de sublinhar o caráter definitivo das derrotas narradas, já que para ninguém o impasse pode ser tão profundo, ou mais sem saída a situação, do que para aquele a quem não é dada uma perspectiva mais ampla ou distanciada do problema.

Mas esse pessimismo todo não aponta necessariamente para uma "nacionalidade desarmada para viver”, como diagnosticou Mário de Andrade. 
Ao contrário, trata-se de uma nacionalidade que pretende mostrar sua força e seu aparelhamento para a vida ao encarar e incorporar o fracasso ao invés de escapulir para outros planos - para o plano que os próprios romancistas de 30 chamariam de meramente estético, por exemplo.

E neste ponto já se introduz a segunda questão que o texto de Mário de Andrade propõe, ou seja, que visão da nacionalidade o romance de 30 consagrou. E é preciso admitir nele a ausência de projetos totalizadores. No modernismo, produção artística e busca de uma identidade nacional estão articuladas, integradas, tanto na obra de Mário de Andrade quanto na de Oswald de Andrade ou na dos autores do verdeamarelismo. Tais propostas de uma visão de nacionalidade, expostas em manifestos, eram, em geral, uma forma de articular passado e presente que dava sustentação à utopia modernista.

Distante da utopia da vanguarda, os anos 30 assistiram a um outro tipo de comportamento por parte dos escritores. Ninguém propôs visões nem mais nem menos unificadoras de Brasil. Foi uma produção atomizada. Sem ver a possibilidade de propor algum tipo de ação prospectiva imediata, cada romancista se ocupou de mergulhar num aspecto específico do presente. Só é possível tentar enxergar alguma visão geral do país após uma leitura extensiva desses romances - e mesmo a maneira pela qual Mário de Andrade percebeu a importância da figura do fracassado demonstra isso. Não foi algo colhido em qualquer proposição sistematizada, mas sim num processo de acumulação, na leitura de uma série de romances, incluindo vários de que ninguém mais fala hoje. $\mathrm{E}$ é esse um dos maiores problemas para o estudo do romance de 30. Sendo uma produção atomizada e ancorada no presente, sujeita às exigências imediatas, acabou produzindo poucas obras que as gerações de críticos que a sucederam julgaram aptas a integrar nosso cânone literário. Somente no conjunto, extenso e muitas vezes desinteressante, é que se pode perceber esse mergulho coletivo na tentativa de compreensão do momento presente. Não havendo projeto coletivo, há no entanto um desigual movimento coletivo que inclui todo o regionalismo - assumido ou não, já que mesmo em livros inequivocamente "intimistas" Lúcio Cardoso tira grande partido do ambiente das cidadezinhas do interior de Minas, por exemplo -, mas também o romance urbano ambientado tanto nas metrópoles do Rio de Janeiro e São Paulo quanto nas capitais periféricas ou cidades de médio porte como Santos ou Petrópolis. 
Além disso, esse interesse pelo fracassado foi responsável direto por uma das maiores conquistas do romance de 30 para a ficção brasileira que viria a seguir: a incorporação das figuras marginais. Assim como é possível falar das dificuldades que o romance de 30 teria para se afirmar sem o modernismo, é possível especular sobre como teria sido difícil a aceitação do sertanejo de Guimarães Rosa ou da mulher de Clarice Lispector sem a legitimação literária que o romance de 30, em suas várias vertentes, acabou conquistando para essas criaturas marginais alçadas a protagonistas.

O resultado é que com esse procedimento anti-escola, voluntariamente ou não, os romancistas de 30 produziram uma vigorosa força de oposição a uma visão “total” - totalitária mesmo - de Brasil proposta por Getúlio Vargas. É um contraste significativo o que se cria entre a visão do país como um conjunto de realidades locais que merece ser conhecido nas suas particularidades e o modelo oficial de unidade nacional, cuja tendência seria a de apagar as diferenças para se obter um conceito uno de nação. ${ }^{5} \mathrm{~A}$ boa recepção ao romance regionalista, por exemplo, mesmo considerando as acanhadas dimensões de nosso público leitor àquela altura, foi uma demonstração clara da distância de um projeto oficial unificador em relação à visão que ia se tornando a mais viável para os próprios brasileiros, que queriam simplesmente saber da vida nos engenhos, do drama da seca, da região amazônica, das plantações de cacau e café, da realidade dos pampas, dos novos bairros que surgiam em Belo Horizonte e mais.

\section{BIBLIOGRAFIA}

ANDRADE, Mário de. Vida literária. São Paulo, Hucitec/Edusp, 1993. Edição de Sonia Sachs.

—. Aspectos da literatura brasileira. 5 ed. São Paulo: Martins, 1974.

Quem formulou exemplar e radicalmente esse tipo de pretensão unificadora foi o Integralismo, desde seu manifesto de outubro de 1932. Em artigo de jornal de 1945, reproduzido por Edgard Carone em A Segunda República (CARONE, 1973), o próprio Plínio Salgado recupera sua concordância com Getúlio Vargas acerca do "perigo" do regionalismo para a construção dessa idéia de nação. 
—.Cartas a Murilo Miranda. Rio de Janeiro, Nova Fronteira, 1981.

CAMPOS, Haroldo de. Poesia e modernidade: o poema pós-utópico. In: Folhetim - Folha de São Paulo. São Paulo: 404, 14/10/1984.

CANDIDO, Antonio. A revolução de 1930 e a cultura. In: A educação pela noite e outros ensaios. São Paulo: Ática, 1987.

CARONE, Edgard. A segunda república. São Paulo: Difel, 1973.

CASTRO. Moacyr Werneck de. Mário de Andrade: Exílio no Rio. Rio de Janeiro, Rocco, 1989.

LIMA, Benjamin. Esse Jorge de Lima! Rio de Janeiro: Adersen, 1933.

QUEIRÓS, Eça de. Obras. Porto: Lello, s/d.

RAMOS, Graciliano. São Bernardo. 45 ed. Rio de Janeiro: Record, 1985.

REGO, José Lins do. Espécie de história literária. In: Lanterna Verde. Rio de Janeiro: 6 , abr. 1938

SCHWARZ, Roberto. A carroça, o bonde e o poeta modernista. In: Que horas são? São Paulo: Companhia das Letras, 1987. 